\title{
Medical Students' Feedback of Applying the Virtual Dissection Table (Anatomage) in Learning Anatomy: A Cross-sectional Descriptive Study
}

\author{
Wardah Abdullah Alasmari \\ Department of Anatomy, Faculty of \\ Medicine, Umm Al-Qura University, \\ Makkah, Saudi Arabia
}

\begin{abstract}
Objective: Conventional cadaver dissection is the main learning tool for studying human anatomy. Other tools have been developed to add another dimension of depth to anatomy teaching, such as Anatomage. 3D Anatomage is a touch interactive anatomy virtual dissection table used in anatomy education. The aim of this study was to address students' opinions on applying the virtual dissection table (3D Anatomage) as an additional tool to cadaver dissection in learning anatomy.

Methods: An electronic questionnaire consisted of 6 questions that included items regarding the effect of using 3D Anatomage on students' deep understanding of anatomy topics, the locations and relationships of the different internal body structures and the application of anatomical knowledge. The survey was completed by 78 medical students.

Results: The results of this study showed that the majority of students preferred using 3D Anatomage as an additional tool to cadaver dissection for learning anatomy since it enhances active learning, and approximately $89 \%$ of students agreed that 3D Anatomage helped them to better understand the relationships between internal structures and visualizing the body system. Additionally, approximately $72 \%$ of the students indicated that the imaging facility in 3D Anatomage was useful for enabling their understanding of anatomy as it is envisioned through medical imaging.
\end{abstract}

Conclusion: In conclusion, using the 3D Anatomage virtual dissection table is effective in anatomy education, and its use is recommended as an anatomy learning resource in addition to cadavers.

Keywords: anatomy education, cadaver dissection, Anatomage

\section{Introduction}

Anatomy is considered to be a cornerstone in learning medicine. Cadaver dissection is the main learning tool for studying human anatomy. ${ }^{1}$ During dissection, the internal body organs and structures are exposed and demonstrated to the students who use their sense of touch and vision to help them understand the human body. ${ }^{2,3}$ However, occasionally, access to cadavers may be limited due to the costs, the need for donated bodies and the time consumption for embalming, dissection, and disposal procedures. ${ }^{4}$ Handling with human bodies in anatomical dissection room and disposal of the human remains should be in an ethical manner. ${ }^{5,6}$

Studies suggest that the addition of learning technology resources that stimulate interest in anatomy help to develop deeper approaches to learning, which encourage higher-order thinking, and consequently increase knowledge retention. ${ }^{7}$ Other techniques have been developed to add another dimension of depth to anatomy
Correspondence: Wardah Abdullah Alasmari

Department of Anatomy, Faculty of

Medicine, Umm Al-Qura University,

Makkah, Saudi Arabia

Email waasmari@uqu.edu.sa 
teaching, such as 3D Anatomage, which is a touch Interactive Anatomy Dissection Table.

Anatomage was developed by a company located in California in collaboration with the Stanford Clinical Anatomy Department. Basically, it was created using stereoscopic images of different human body parts that are reconstructed in an accurate 3-dimensional (3D) representation of the human body using software. The user can dissect the digital body and peel off the skin to display muscles, the skeleton, internal organs, nerves, and blood vessels. Additionally, longitudinal, sagittal and horizontal sections can be made to understand the relationships between different parts of the body and internal organs. The gender can be changed since the images that were originally taken came from both male and female cadavers. The table also has an imaging facility to show how the anatomy is envisioned through medical imaging, which supports the software's integration in teaching of anatomy and imaging. After finishing a virtual dissection, a user can reset the digital body so that it is ready for another session, and thus Anatomage can be used repeatedly with no restrictions. ${ }^{8-10}$

In the Department of Anatomy at the College of Medicine, Umm Al-Qura University, cadaver dissection and 3D Anatomage are both used in teaching and learning anatomy. The main anatomical topics in the sessions are addressed using cadavers/dissected specimens, and then certain questions/tasks related to anatomical issues and their clinical correlation in the lesson are discussed in small teaching groups using 3D Anatomage. Therefore, the students are actively involved in conducting these tasks using 3D Anatomage, which enhances the students' participation in the learning process, and they become active not passive learners.

Therefore, the aim of this study was to address students' opinions on utilizing the virtual dissection table (3D Anatomage) technology as an additional tool to dissected specimens in learning anatomy and its effects on students' deep understanding of the locations and relationships among different internal body structures.

\section{Methods}

The virtual 3D Anatomage table was applied in anatomy teaching in the Department of Anatomy College of Medicine, Umm Al-Qura University (UQUMED) starting with the 2017-2018 academic year. This study used an electronic questionnaire consisting of 6 questions (Figure 1A-F) addressing students' perceptions of applying the 3D Anatomage table as additional resource to cadaver dissection in anatomy education (Appendix). The survey included items regarding the clarity and deep understanding of the topic and the application of anatomical knowledge. Different anatomical topics were covered extensively during the 2nd and 3rd years of medical school. The questionnaire was completed by 78 medical students who studied anatomy using 3D Anatomage alongside conventional cadaver dissection in the Department of Anatomy at College of Medicine, Umm Al-Qura University. The responses were collected at the end of the third year after finishing anatomy lessons in the dissection room. The data were analyzed using Excel. Frequencies and percentages were calculated.

The study was approved by the Biomedical Research Ethics Committee, Faculty of Medicine, Umm Al-Qura University, Makkah, Saudi Arabia. All participants provided informed consent, in accordance with the Declaration of Helsinki.

\section{Results}

The questionnaires' results showed that $81 \%(n o=63 / 78)$ of the students preferred using 3D Anatomage as an additional tool to cadaveric dissected specimens in learning anatomy. The majority of $73 \%(n o=57 / 78)$ of the students indicated that they benefitted from applying the virtual 3D Anatomage in anatomy education (Figure 1). More than two-thirds $(73 \%)(n o=57 / 78)$ of the students found that applying 3D Anatomage during anatomy practical sessions with the engagement of students in the discussion enhanced active learning (Figure 1). 86\% (no=67/78) of students strongly agreed that making sagittal, parasagittal, coronal and transverse sections of the digital body in 3D Anatomage (Figure 2) boosts their understanding of the locations and relationships of the different internal body structures (Figure 1). A high proportion of $90 \%$ (no=70/ 78) of the students believed that the ability to rotate the digital body and dissect in 3D Anatomage helps in visualizing the body system (Figure 1). More than two-thirds $(72 \%)(n o=56 / 78)$ of the students preferred the incorporation of imaging in 3D Anatomage, since it enables them to understand anatomy envisioned through medical imaging (Figure 1).

The end of the questionnaire was open-ended for any further comments, and one student declared the following: "It absolutely adds to my learning, I suggest allowing students to use it freely under close observation". 
A
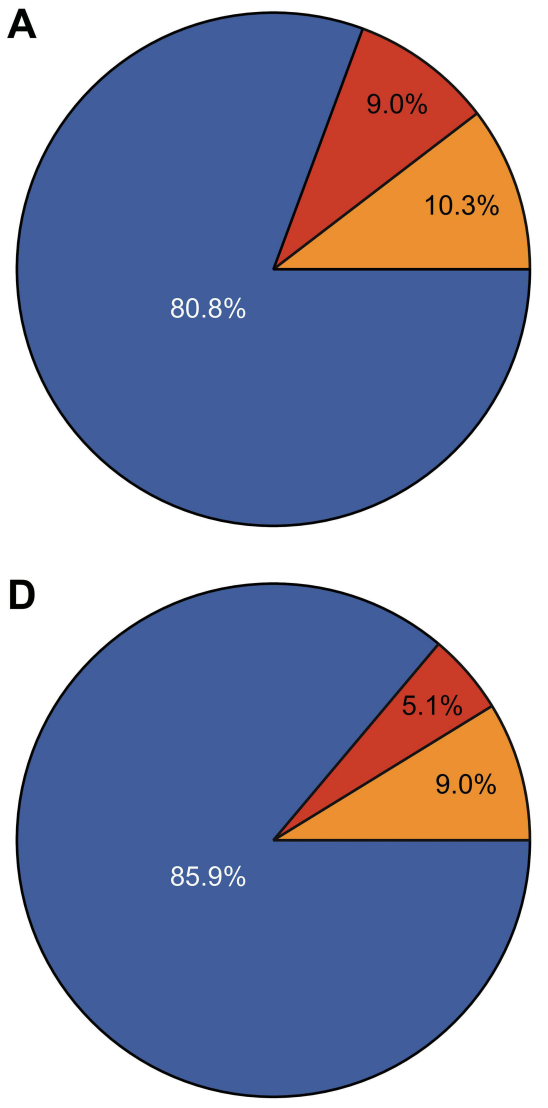

B

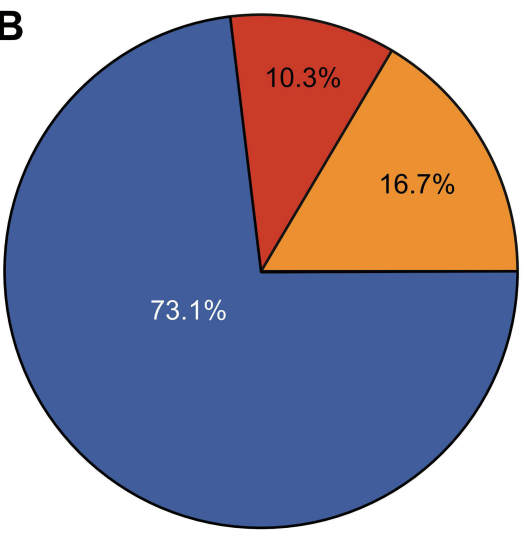

E

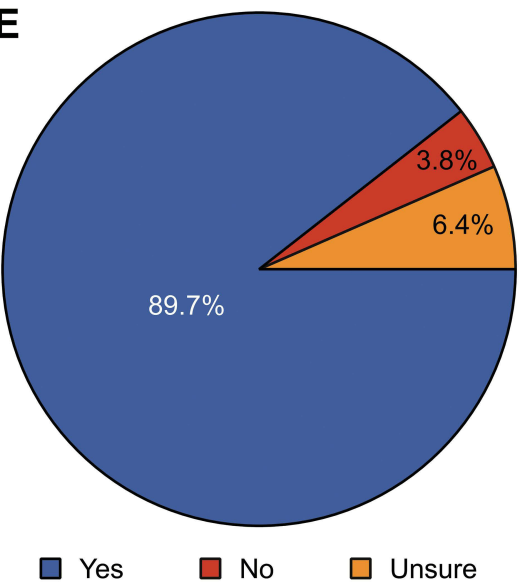

C

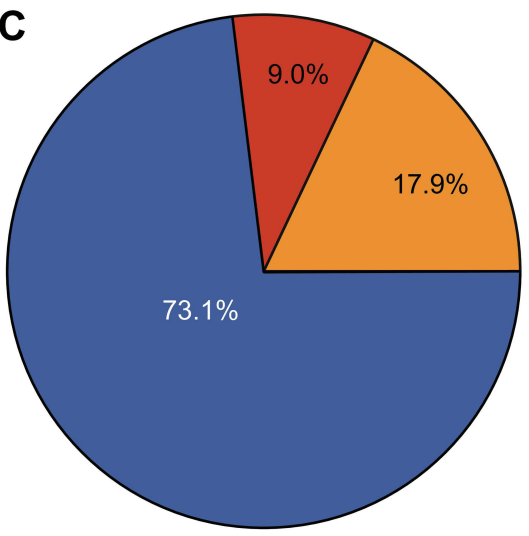

$\mathbf{F}$

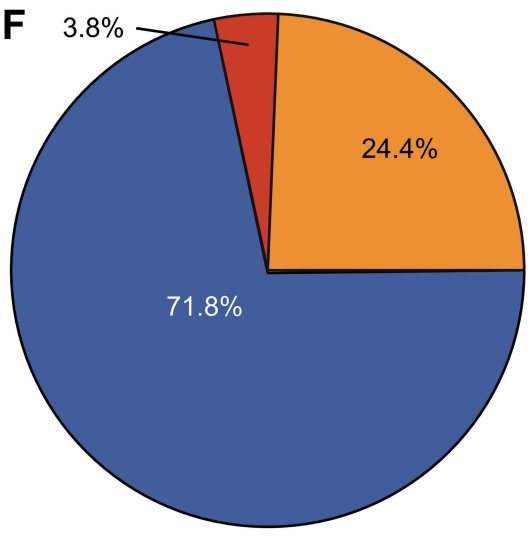

Figure I Comparing the students' responses with yes (blue), no (red) and unsure (Orange). (A) Do you find that using 3D Anatomage as an additional tool to cadaveric dissected specimens is useful for learning anatomy? (B) Did you benefit from applying 3D Anatomage in learning anatomy? (C) Do you find that using 3D Anatomage during anatomy practical sessions enhances active learning? (D) Do you think that the ability to make sections of the body (sagittal, parasagittal, coronal and transverse) in 3D Anatomage enhances your understanding of the locations and relationships of different internal body structures? (E) Do you think that the ability to rotate the body and dissect in 3D Anatomage helps in visualizing the body system? (F) Do you think that incorporation of imaging in 3D Anatomage enables your understanding of anatomy as it is envisioned through medical imaging?

However, another feedback was "It has cons though, very sensitive and sometimes it lags".

\section{Discussion}

The introduction of the virtual dissection table 3D Anatomage in anatomy education has been increased. The incorporation of modern technology is inspiring ways to learn anatomy. ${ }^{11}$ Anatomage has some advantages compared to the use of cadavers, since the cost is minimal because of its unlimited use. There is no time consumption for embalming, dissection and disposal procedures. Additionally, the ability to study different human body parts in accurate 3Ds view and make longitudinal, sagittal and horizontal sections are beneficial to the deep understanding of anatomy. The CT/MRI imaging integration in the table is useful for applying anatomical knowledge in clinical practice.
However, the cons of using Anatomage are the variation in the human body (supernumerary muscles, variation in patterning of nerves and blood vessels) cannot be apparent onto the Anatomage table Moreover, the sense of touch of vessels, nerves and internal body structures cannot be gained, and the color of tissues is different from real ones. ${ }^{11,12}$ The variation in the learning resources of the anatomy using cadaver dissection and 3D Anatomage help in developing deeper learning, which increases knowledge retention and its clinical relevance. ${ }^{7,13}$ Therefore, 3D Anatomage was implemented in anatomy teaching in addition to cadaver dissection in the department of anatomy at UQUMED.

The present study aimed to assess students' opinions of this newly introduced virtual 3D Anatomage in terms of anatomy learning and its contribution to a deep understanding of core anatomical knowledge. The results of this study showed that $81 \%$ of the participating students 


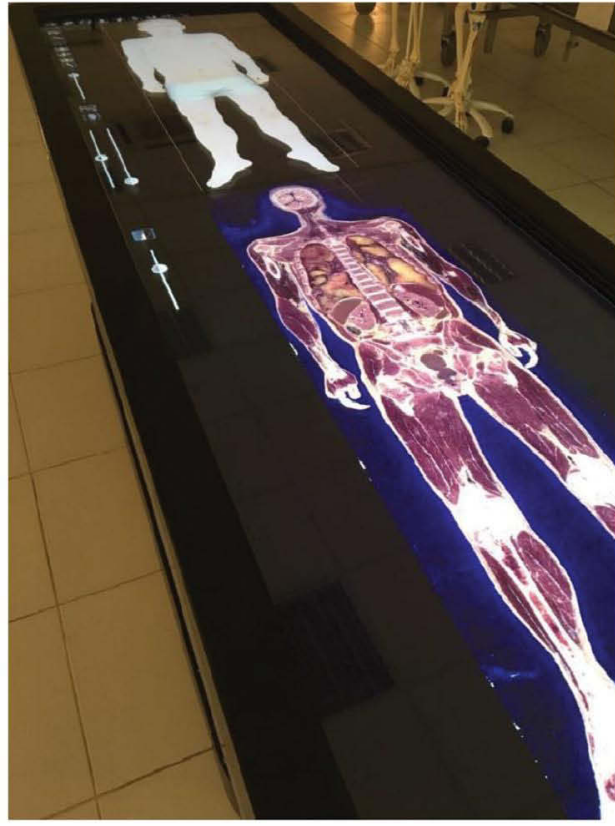

Figure 2 Different spatial planes of internal body structures in 3D Anatomage.

favored the utilization of 3D Anatomage as additional tool to cadavers to acquire a better understanding of anatomy. The majority of them benefitted from applying this new learning resource in anatomy education. Similarly, Custer and Michael $^{14}$ found that imaging science students appreciated using Anatomage since it had a positive influence on their learning anatomy experience. Brown et $\mathrm{al}^{15}$ found that the interactive nature of the Anatomage virtual dissection table made students more engaged in the learning process. Similarly, our students found that applying this strategy that allowed them to answer questions, discuss and share thoughts on certain anatomical knowledge using Anatomage enhanced active learning. ${ }^{16,17}$ Accordingly, this would help to develop skills for scientific reasoning, self-dependent study, the value of teamwork and interpersonal skills. ${ }^{18-20}$

In the present study, $86 \%$ of students agreed that the sectional planes in Anatomage improved the ability to identify the relative locations of different internal body structures. It also showed that $90 \%$ of the participating students believed that Anatomage helps in visualizing the body system due to the ability to rotate the digital body and accordingly provided a better understanding of Anatomy. In agreement with the findings of this study, it has been found that students understand the locations and relationships of different internal structures when utilizing Anatomage compared to the

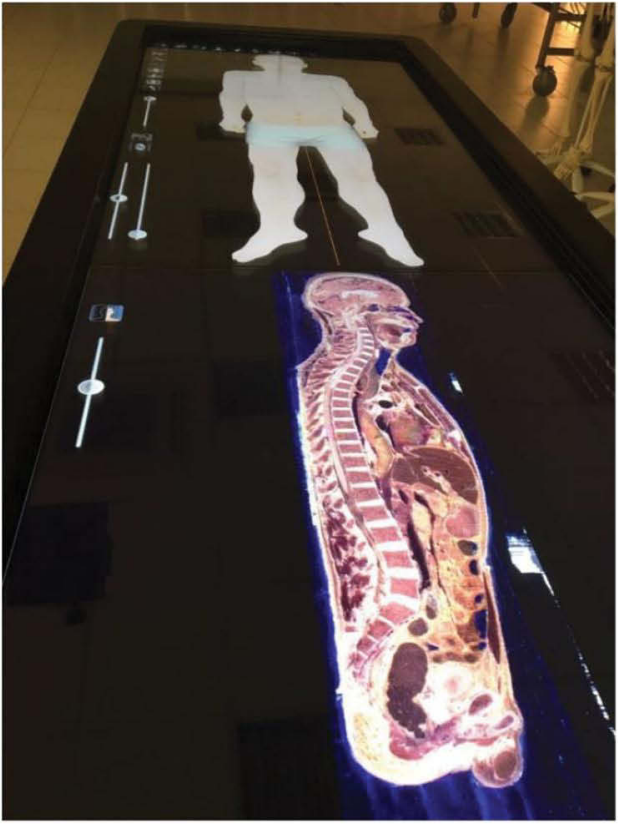

students using cadaver dissection. ${ }^{12,21,22}$ Moreover, a high proportion of participating students benefitted from the integration of imaging in 3D Anatomage, since it enabled them to understand how anatomy envisioned through medical imaging prepared them for clinical practice.

In conclusion, this study was aimed to address students' feedback on applying 3D Anatomage as an additional tool to conventional cadaver dissection in learning anatomy. Based on the results of this study and others, using the $3 \mathrm{D}$ Anatomage virtual dissection table is useful in anatomy education, and it is recommended that it be used as an anatomy learning resource in addition to cadavers. Further studies are required to investigate the effectiveness of Anatomage as an additional tool to cadaver dissection in learning anatomy by comparing students' performance in anatomy in two groups, one group is using only cadaver dissection compared to the other group using Anatomage alongside with dissection. It is also required to examine whether using Anatomage in conjunction with dissection can promote anatomical knowledge retention for long time.

\section{Acknowledgments}

The author is grateful to the medical students who contributed by answering the questionnaire and made this study possible. 


\section{Funding}

There is no funding to report.

\section{Disclosure}

The author declares no conflicts of interest for this work.

\section{References}

1. Johnson JH. Importance of dissection in learning anatomy: personal dissection versus peer teaching. Clin Anat. 2002;15(1):38-44. doi:10.1002/ca.1090

2. McLachlan JC, Patten D. Anatomy teaching: ghosts of the past, present and future. Med Educ. 2006;40(3):243-253. doi:10.1111/ j.1365-2929.2006.02401.x

3. Winkelmann A. Anatomical dissection as a teaching method in medical school: a review of the evidence. Med Educ. 2007;41(1):15-22. doi:10.1111/j.1365-2929.2006.02625.x

4. Creswell JW. Qualitative Inquiry and Research Design. Choosing Among Five Approaches. London: Sage; 2013.

5. Ghosh SK, Kumar A. Building professionalism in human dissection room as a component of hidden curriculum delivery: a systematic review of good practices. Anat Sci Educ. 2019;12(2):210-221. doi:10.1002/ase. 1836

6. Ghosh SK. The practice of ethics in the context of human dissection: setting standards for future physicians. Ann Anatomy. 2020;232:151577. doi:10.1016/j.anat.2020.151577

7. Turney BW. Anatomy in a modern medical curriculum. Ann R Coll Surg Engl. 2007;89(2):104-107. doi:10.1308/003588407X168244

8. Ruiz V. The Anatomage table - visualizing life size anatomy. Street Anatomy. 2013.

9. Fredieu JR, Kerbo J, Herron M, Klatte R, Cooke M. Anatomical models: a digital revolution. Med Sci Educ. 2015;25(2):183-194. doi:10.1007/s40670-015-0115-9

10. Allen MA, Kirkpatrick N, Agosto ER. Anatomage table 6. J Electron Resour Med Libr. 2019;16(2):59-66.
11. Martín JG, Mora CD, Henche SA. Possibilities for the use of Anatomage (the anatomical real body-size table) for teaching and learning anatomy with the students. Biomed J. 2018;2:4.

12. Bharati AS, Kumari NS, Rani VS. A study on student perception of virtual dissection table (Anatomage) at GSL medical college, Rajahmundry. Acad Anat Int. 2018;4(2):28-31. doi:10.21276/ aanat.2018.4.2.8

13. Afsharpour S, Gonsalves A, Hosek R, Partin E. Analysis of immediate student outcomes following a change in gross anatomy laboratory teaching methodology. J Chiropr Educ. 2018;32(2):98-106. doi:10.7899/JCE-17-7

14. Custer TM, Michael K. The utilization of the Anatomage virtual dissection table in the education of imaging science students. $J$ Tomogr Simul. 2015;1:1-4.

15. Brown J, Stonelake S, Anderson W, et al. Medical student perception of Anatomage-a 3D interactive anatomy dissection table. Int J Surg. 2015;1(23):S17-8.

16. Gross M, Masters C. Virtual dissection: using active learning with the Anatomage table to enhance student learning. FASEB J. 2017;31(S1):1b9.

17. Paech D, Giesel FL, Unterhinninghofen R, Schlemmer HP, Kuner T, Doll S. Cadaver-specific CT scans visualized at the dissection table combined with virtual dissection tables improve learning performance in general gross anatomy. Eur Radiol. 2017;27(5):21532160. doi:10.1007/s00330-016-4554-5

18. Nelson C. Fostering Critical Thinking: Comments and Conversations. The Center for Excellence in Learning and Teaching (CELT). Brockport, NY: The College at Brockport, State University of New York; 2006.

19. Karge BD, Phillips KM, Jessee T, McCabe M. Effective strategies for engaging adult learners. $J$ Coll Teach Learn. 2011;8(12):53-56.

20. Estai M, Bunt S. Best teaching practices in anatomy education: a critical review. Ann Anat. 2016;208:151-157. doi:10.1016/j.anat.2016.02.010

21. Fyfe G, Fyfe S, Dye D. Use of Anatomage tables in a large first year core unit. In: Carter H, Gosper M, Hedberg J, editors. ASCILITEAustralian Society for Computers in Learning in Tertiary Education Annual Conference. Australia: Australasian Society for Computers in Learning in Tertiary Education; 2013:298-302.

22. Periya SN, Moro C. Applied learning of anatomy and physiology: virtual dissection tables within medical and health sciences education. Bangk Med J. 2019;15(1):121. doi:10.31524/bkkmedj.2019.02.021
Advances in Medical Education and Practice

\section{Publish your work in this journal}

Advances in Medical Education and Practice is an international, peerreviewed, open access journal that aims to present and publish research on Medical Education covering medical, dental, nursing and allied health care professional education. The journal covers undergraduate education, postgraduate training and continuing medical education including emerging trends and innovative models linking education, research, and health care services. The manuscript management system is completely online and includes a very quick and fair peer-review system. Visit http://www.dovepress.com/testimonials.php to read real quotes from published authors. 